Original Research Paper

\title{
Detection of Pesticide Residue in Dams and Well Water in Jazan Area, Saudi Arabia
}

\author{
${ }^{1}$ Hasan Y. Al-Hatim, ${ }^{1}$ Deifalla Alrajhi and ${ }^{2}$ Abdul Jabbar Al-Rajab \\ ${ }^{I}$ Department of Plant Protection, College of Food Sciences and Agriculture, King Saud University, Riyadh, Saudi Arabia \\ ${ }^{2}$ Center for Environmental Research and Studies, Jazan University, Jazan, Saudi Arabia
}

\author{
Article history \\ Received: 04-08-2015 \\ Revised: 14-09-2015 \\ Accepted: 23-09-2015 \\ Corresponding Author: \\ Abdul Jabbar Al-Rajab \\ Center for Environmental Research \\ and Studies, Jazan University, \\ Jazan, Saudi Arabia \\ E-mail: alrajab@hotmail.com
}

\begin{abstract}
The application of pesticides indoors and on agricultural lands increased dramatically in recent years in the Jazan area (Saudi Arabia) to control termites and the vectors of diseases, such as Rift Valley Fever (RVF) and malaria. This practice increased the potential risk of pesticide contamination of surface water and groundwater. In this study, samples of 44 wells and 3 dams were collected; the samples were analysed for the presence of 15 pesticides used in the Jazan area. The results showed that the most detected compounds in the surface water samples were diazinon, Dichlorodiphenyltrichloroethane (DDT), fenitrothion and cyfluthrin, with average concentrations of $0.098,0.104,0.321$ and $0.394 \mu \mathrm{g} \mathrm{L} \mathrm{L}^{-1}$, respectively. In the groundwater samples, the most detected insecticides were diazinon, dieldrin and fenthion, with average concentrations of 0.117 , 0.005 and $0.472 \mu \mathrm{g} \mathrm{L}^{-1}$, respectively. In general, detected concentrations of organophosphorus insecticides slightly exceeded the allowed Maximum Residue Limit (MRL) of the European Union, which is $0.1 \mu \mathrm{g} \mathrm{L}^{-1}$, in some samples. However, the findings of this study about the safety of water resources in the Jazan area were not alarming because the detected concentrations were below the MRL and lower than the limit of the sum of all individual compounds detected in the same sample. More extended investigations are highly recommended.
\end{abstract}

Keywords: Groundwater, Dam, Contamination, Insecticide, Residues, Jazan, Saudi Arabia

\section{Introduction}

The use of pesticides worldwide has increased significantly in recent years because of developments in agricultural production and to control various diseases in developing countries, such as Rift Valley Fever (RVF) and malaria (Yadav et al., 2015; Köck-Schulmeyer et al., 2014; Akesson et al., 2013; Zhao and Pei, 2012; Al-Rajab et al., 2008; Sarigiannis et al., 2013). The yearly worldwide consumption of pesticides was estimated to be about 2 million tons, with heavy consequences of around 3 million people poisoned and about 200,000 deaths because of these chemicals (Yadav et al., 2015). Pesticides reach agricultural land either directly, through the application on target plants, or indirectly, though the use of effluents from Wastewater Treatment Plants (WWTPs) as fertilizer (biosolids) or through irrigation (liquid municipal biosolids) (Fenoll et al., 2014; Al-Rajab and Hakami,
2014). Once the pesticide reaches the soil, the soil constituents will absorb a part of compound, while other parts remain in the soil solution and might be available for a potential transfer to surface water or groundwater (Seth, 2014; Al-Rajab and Schiavon, 2010). Contamination of surface water has been reported worldwide, albeit at low concentrations (Otieno et al., 2014; Robles-Molina et al., 2014). Belenguer et al. (2014) reported the presence of 23 different pesticides, some forbidden in the European Union (EU), in the water samples of the Jucar River in Spain; the concentrations ranged from $0.09 \mathrm{ng} \mathrm{L}^{-1}$ (ethion) to $171.5 \mathrm{ng} \mathrm{L}^{-1}$ (imazalil). Robles-Molina et al. (2014) reported similar results. They showed the contamination of water samples collected from the Guadalquivir River in Spain with 25 pesticides belonging to different groups at concentrations varied from $1 \mathrm{ng} \mathrm{L} \mathrm{L}^{-1}$ (methoxychlor) to $5166.9 \mathrm{ng} \mathrm{L}^{-1}$ (dimethoate).

Groundwater vulnerability to pesticides varies within and between major aquifer units (Worrall and Besien, 
2005). Pesticide contamination of groundwater has been reported in different studies worldwide. Shukla et al. (2006) determined the contamination of groundwater in all samples collected from 28 domestic wells in Hyderabad, India, at concentrations ranging from 0.15 $2.14 \mu \mathrm{g} \mathrm{L}^{-1}$ for 4 organochlorine pesticides, such as Dichlorodiphenyltrichloroethane (DDT), lindane, $\alpha$ Endosulfan and $\beta$-Endosulfan. Vryzas et al. (2012) reported that almost all water samples collected from 37 wells in Greece for 5 years were contaminated by pesticides at concentrations up to $5.2 \mu \mathrm{g} \mathrm{L}^{-1}$. Reemtsma et al. (2013) reported the same observation in Germany; 58 samples of groundwater were contaminated at the median total concentrations of pesticide metabolites of $0.62 \mu \mathrm{g} \mathrm{L}^{-1}$. Morvan et al. (2006) reported the contamination of groundwater in France with atrazine and Deethylatrazine (DEA) at concentrations ranging from $0.07-1.16 \mu \mathrm{g} \mathrm{L}^{-1}$.

Groundwater is the main source (about 96\%) of fresh water in the world. However, in Saudi Arabia, drinking water is almost entirely provided by groundwater.
Pesticide pollution of groundwater has been reported in several countries (Malaguerra et al., 2012; Vryzas et al., 2012; Sahoo et al., 2005). Exposure to pesticides, either occupationally or environmentally, causes a range of human health problems (Abhilash and Singh, 2009).

Currently, Saudi Arabia is among the largest agricultural producer in the Middle East and pesticides are heavily used in plant protection and in the control of different disease vectors. Jazan (16.4-18.33 ${ }^{\circ} \mathrm{N}, 41.4$ $\left.43.4^{\circ} \mathrm{E}\right)$ is the smallest province in Saudi Arabia and covers an area of $13500 \mathrm{~km}^{2}$ in the Southwest of the kingdom; it has a population of about 1.5 million (Fig. 1). Jazan is the most important province in Saudi Arabia in agricultural production and the control of some diseases, such as RVF and malaria, requires the use of insecticides to keep the population of their vectors under control. This practice increases the potential risk of pesticide contamination of surface water and groundwater which may be related to some diseases and health problems such as cancer or organ damage if found at high concentrations (Seth, 2014).

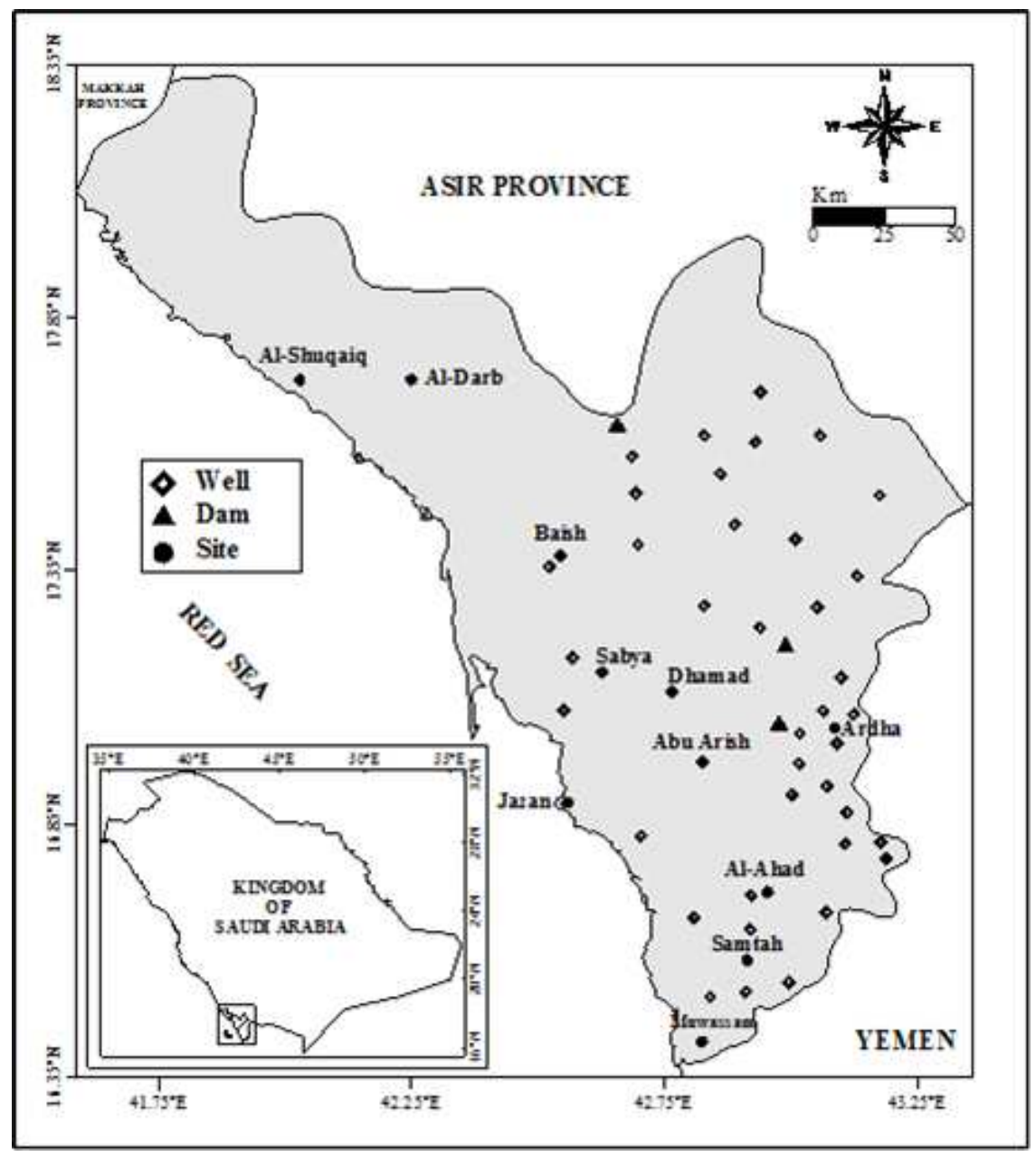

Fig. 1. Map of the study area location, Jazan, Saudi Arabia 
Information on the assessment and management of environmental exposure to pesticides is particularly scarce in Jazan. In this study, the occurrence of pesticides in 44 wells and 3 dams of the Jazan province have been investigated. To the best of our knowledge, this is the first work in the Jazan area on the occurrence of pesticides in surface water and groundwater.

\section{Materials and Methods}

\section{Chemicals}

Dieldrin $10 \mathrm{ng} \mu \mathrm{L}^{-1}$ in cyclohexane; para,para'Dichlorodiphenyldichloroethane (p,p'-DDD), purity 99.9\%; Dichlorodiphenyldichloroethylene (DDE), purity 99\%; and DDT $10 \mathrm{ng} \mu \mathrm{L}^{-1}$ in cyclohexane were purchased from Fisher Scientific (USA). Diazinon, purity $99.5 \%$; fenitrothion, purity $98 \%$; pirimiphosmethyl, purity $99.5 \%$;malathion, purity $95.5 \%$; fenthion, purity $98.7 \%$; cyhalothrin, purity $98 \%$; cyfluthrin, purity $95.5 \%$; cypermethrin, purity $92 \%$; deltamethrin, purity 99.5\%; tetramethrin, purity $95.3 \%$; Bioallethrin, purity 93.8\%; and piperonyl butoxide, purity 95\% were purchased from Chem Service (USA). Methanol, methyl acetate and methylene chloride (High-Performance Liquid Chromatography [HPLC] grade) were purchased from Sigma-Aldrich Chemie GmbH (Switzerland).

\section{Sampling}

A total of 53 water samples were collected and analysed. Samples were collected from 44 wells and 3 dams in the Jazan province (Saudi Arabia) during summer 2005 (Fig. 1). The sampling was carried out as described by Van Stempvoort et al. (2014). Groundwater samples were collected from wells at an approximate depth of $1.0 \mathrm{~m}$ below the surface. Samples from dams were collected from 3 different places at a shallow depth within $3.0 \mathrm{~m}$ of the edge of the dam using a simple homemade 1 L High-Density Polyethylene (HDPE) sampler; 3 samples of $1 \mathrm{~L}$ were collected from each site or well. Samples were filtered on site using membrane filters $0.45 \mu \mathrm{m}$ (VWR, Germany); they were then transferred to 1 L HDPE bottles (Naizak, Saudi Arabia). A few drops of $\mathrm{HCl} 1 \mathrm{M}$ were added to each sample to reduce the $\mathrm{pH}$ to prevent the biodegradation of compounds. Samples were identified and they were transferred to the lab refrigerated at $4^{\circ} \mathrm{C}$ in an ice cooler. Samples were analysed at the central lab of King Saud University within 10 days after sampling.

\section{Extraction}

Sixteen compounds were selected to be analysed based on the pesticide application history in the area, either in agriculture or in mosquito control. Each sample of $1 \mathrm{~L}$ was extracted by Solid Phase Extraction (SPE) for the 16 compounds. A recovery test for the extraction method was made using distilled water samples amended with a known amount of each pesticide. The SPE-disk $\mathrm{C}_{18}$ (VWR, Germany) was conditioned with $5 \mathrm{~mL}$ ethyl acetate and with $5 \mathrm{~mL}$ chloride methylene before washing it with $10 \mathrm{~mL}$ methanol. Finally, $10 \mathrm{~mL}$ of distilled water was added to keep the disk wet. The $1 \mathrm{~L}$ amended sample was added to a $2 \mathrm{~L}$ separation funnel, 5 $\mathrm{mL}$ of methanol was added to the sample and hand shaken for $2 \mathrm{~min}$ and the whole sample was filtered through the conditioned SPE-disk $\mathrm{C}_{18}$. The pesticides were recovered from the cartridge by adding $5 \mathrm{~mL}$ of ethyl acetate and $5 \mathrm{~mL}$ of chloride methylene separately. Another $2 \mathrm{~mL}$ chloride methylene was added and the collected solvents were evaporated using a rotary evaporator (Buchi Rotavapor R110, Switzerland) at $35^{\circ} \mathrm{C}$ until the dryness point. They were then recovered with $1 \mathrm{~mL}$ of methanol and kept refrigerated at $4^{\circ} \mathrm{C}$ until analysis. A blank of distilled water was extracted at the same time as control. The recovery rate for the selected compounds was acceptable at the range of $71-124 \%$ of the initial amount (Table 1).

\section{Analytical Methods}

Residues were determined using a GC/MS Agilent 6890 (USA) equipped with a mass selective detector (MSD Agilent 5973, USA), micro-electron capture detector ( $\mu \mathrm{ECD}$, Agilent, USA) and a thermionic detector (Nitrogen-Phosphorus Detector [NPD], Agilent, USA). A capillary Agilent HP-5 column $(30 \mathrm{~m} \times 0.32 \mathrm{~mm}$, film thickness $0.25 \mu \mathrm{m}$ ) was used. The carrier gas was helium at a flow rate of $2 \mathrm{~mL} \mathrm{~min}^{-1}$ with makeup gas $\mathrm{N}_{2}$ at a flow rate of $60 \mathrm{~mL} \mathrm{~min}{ }^{-1}$. A splitless mode for the 3 detectors was adopted $\left(26.34 \mathrm{psi}, 200^{\circ} \mathrm{C}\right)$. The oven temperature was programmed at $40-200^{\circ} \mathrm{C}$ at $30^{\circ} \mathrm{C} \mathrm{min}^{-1}$ and $200-280^{\circ} \mathrm{C}$ at $30^{\circ} \mathrm{C} \mathrm{min}^{-1}$. Finally, the temperature was kept at $280^{\circ} \mathrm{C}$ until the end of injection at $60 \mathrm{~min}$.

Table 1. Recovery rate of different pesticides using extraction with SPE-Disk $\mathrm{C}_{18}$

\begin{tabular}{ll}
\hline Compound & Recovery rate \pm SD $(n=4)$ \\
\hline Dieldrin & $90.3( \pm 2.5)$ \\
DDE & $88.7( \pm 0.8)$ \\
DDD & $89.0( \pm 1.2)$ \\
DDT & $100.5( \pm 3.1)$ \\
Cyhalothrin & $88.0( \pm 1.8)$ \\
Cyfluthrin & $80.6( \pm 2.1)$ \\
Cypermethrin & $74.9( \pm 0.7)$ \\
Deltamethrin & $75.3( \pm 1.1)$ \\
Bioalthrin & $71.7( \pm 3.0)$ \\
Tetramethrin & $124.2( \pm 5.2)$ \\
Piperonyl butoxide & $98.0( \pm 2.7)$ \\
Diazinon & $99.5( \pm 4.1)$ \\
Fenitrothion & $114.1( \pm 2.2)$ \\
Pirimphos-methyl & $98.3( \pm 1.6)$ \\
Malathion & $117.9( \pm 3.3)$ \\
Fenthion & $76.7( \pm 1.4)$ \\
\hline
\end{tabular}


The injected volume was $5 \mu \mathrm{L}$. The linearity of the analytical method was tested using 6 calibration solutions for the selected compounds at the concentrations 0.01 , $0.05,0.1,0.5,1$ and $5 \mu \mathrm{g} \mathrm{mL}{ }^{-1}$. The analysis data were managed by the software ChemStation (USA). Statistical analyses were conducted using StatBox (Version 6.4, Grimmer Software, France), Excel (Microsoft Office 2010, USA) and Sigma Plot 3.10 (USA).

\section{Results}

\section{Occurrence of Pesticides in Groundwater}

Fourteen insecticides of the 16 selected compounds were detected in at least 1 sample each in the 53 analysed samples. The detected compounds were dieldrin, DDD, DDT, cyhalothrin, cyfluthrin, cypermethrin, Bioallethrin, tetramethrin, diazinon, fenitrothion, pirimiphos-methyl, malathion and fenthion. For the organophosphorus compounds, the order of detection frequency was diazinon, fention, malathion, fenitrothion and pirimphosmethyl in 29, 19, 9, 8 and 6 samples respectively. Their concentrations in the samples were ranging between $0.016-0.218,0.015-0.93,0.124-0.211,0.031-0.93$ and $0.126-0.97 \mu \mathrm{g} \mathrm{L}^{-1}$, respectively (Fig. 2 and 3).

The detected organochlorine insecticides were dieldrin, DDT and DDD in 22, 1 and 1 samples, respectively at concentrations ranging between of 0.002-0.008, 0.007 and $0.05 \mu \mathrm{g} \mathrm{L}^{-1}$, respectively (Fig. 2 and 3). However, DDE was not detected in any groundwater sample.

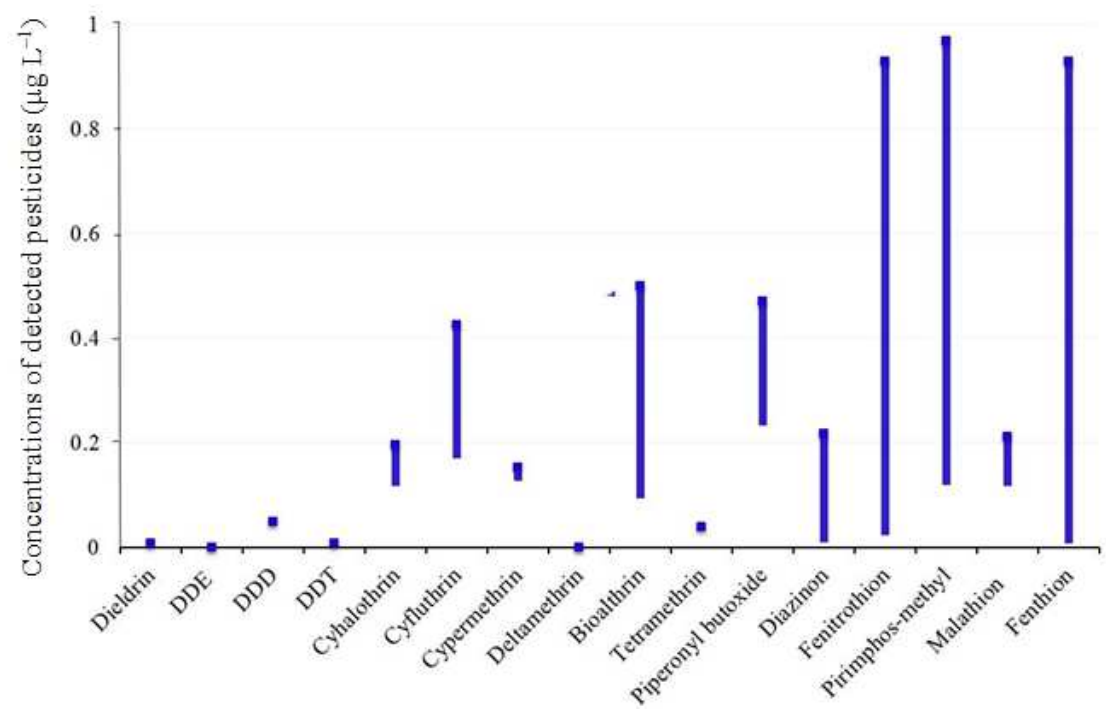

Fig. 2. Concentrations of selected insecticides in groundwater samples $\left(\mu \mathrm{g} \mathrm{L}^{-1}\right)$

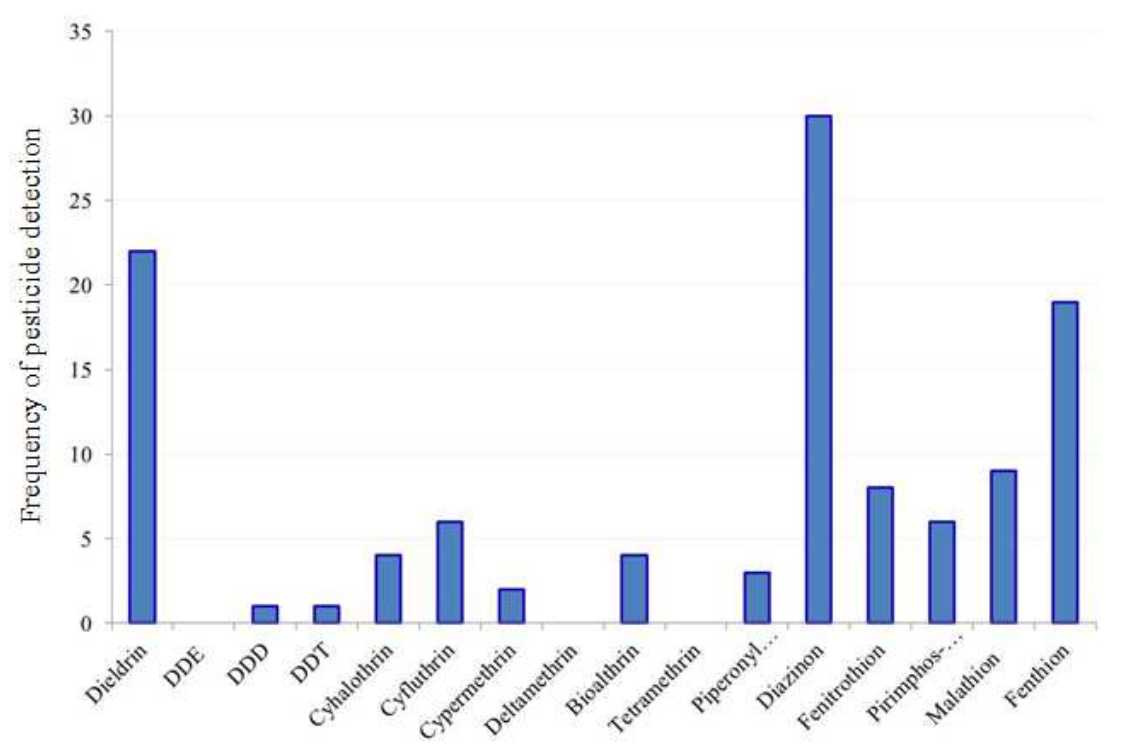

Fig. 3. Frequency of selected compounds detection in groundwater samples 
Otherwise, the pyrethroid insecticides were detected in the following frequency order: Cyfluthrin, cyhalothrin, bioalthrin and cypermethrin in 6, 4, 4 and 2 samples, respectively. Their concentrations were ranging between 0177-0426, 0124-0197, 01-05 and 0134-0154 $\mu \mathrm{g} \mathrm{L} \mathrm{L}^{-1}$, respectively (Fig. 2 and 3). Deltamethrin was not detected in any groundwater sample. The Piperonyl Butoxide (PBO) is an organic compound used in the pesticide formulation to enhance its efficiency. This compound was detected in 3 samples of groundwater at concentrations ranged between 0.24 and $0.47 \mu \mathrm{g} \mathrm{L}^{-1}$ (Fig. 2 and 3). The general frequency of all detected pesticides in groundwater was in the following order: Diazinon, dieldrin, fention, malathion, fenitrothion, pirimphosmethyl, cyfluthrin, bioalthrin, cyhalothrin, PBO, cypermethrin, DDT and DDD (Fig. 2 and 3).

In general, this study detected concentrations of organophosphorus insecticides in all samples that slightly exceeded the allowed Maximum Residue Limit (MRL) of the EU, which is $0.1 \mu \mathrm{g} \mathrm{L}^{-1}$ for an individual pesticide. They were lower than the limit of the sum of all individual compounds detected in the same sample of $0.5 \mu \mathrm{g} \mathrm{L}^{-1}$ (EU, 2006; Daam et al., 2010).

\section{Occurrence of Pesticides in Surface Water (Dams)}

This study comprised all dams of the Jazan area, including Wadi Jazan Dam, Um Khobara Dam and Rayth Dam. In total, 11 compounds were detected in the 3 dams at different concentrations ranging from
0.003-0.534 $\mu \mathrm{g} \mathrm{L}^{-1}$. The detected compounds were dieldrin, DDE, DDT, cyhalothrin, cyfluthrin, cypermethrin, diazinon, fenitrothion, pirimiphosmethyl, malathion and fenthion (Fig. 4 and 5). In the Rayth Dam, 10 compounds were detected at concentrations ranging $0.003-0.534 \mu \mathrm{g} \mathrm{L}^{-1}$. The order of detection frequency of pesticides was diazinon, fenitrothion, pirimphos-methyl, DDT, dieldrin, cyhalothrin, cyfluthrin, cypermethrin, malathion and fention (Fig. 5). In the Wadi Jazan Dam, five compounds were detected at concentrations ranging from $0.1 \mu \mathrm{g} \mathrm{\textrm {L } ^ { - 1 }}$ for diazinon and $0.332 \mu \mathrm{g} \mathrm{\textrm {L } ^ { - 1 }}$ for cyfluthrin (Fig. 4). The order of detection frequency of pesticides was diazinon, fenitrothion, cyfluthrin, DDT and fention (Fig. 5). In contrast, only 2 compounds were detected in the Um Khobara Dam: Dieldrin and DDE at concentrations of 0.003 and $0.005 \mu \mathrm{g} \mathrm{L}^{-1}$, respectively (Fig. 4 and 5).

The frequency of all detected pesticides in surface water (dams) was: Diazinon, fenitrothion, cyfluthrin, DDT, dieldrin, cypermethrin, pirimphos-methyl, fenthion, DDE, cyhalothrin, bioalthrin and malathion (Fig. 4 and 5). The organochlorine insecticide DDT is banned in Saudi Arabia. However, DDT might be infiltrated illegally to some local farmers which explain the presence of this compound and its metabolites DDE and DDD in some water samples. Some investigated pesticides were not detected in any sample of the surface water such as, DDD, deltamethrin, bioalthrin, PBO and tetramethrin.

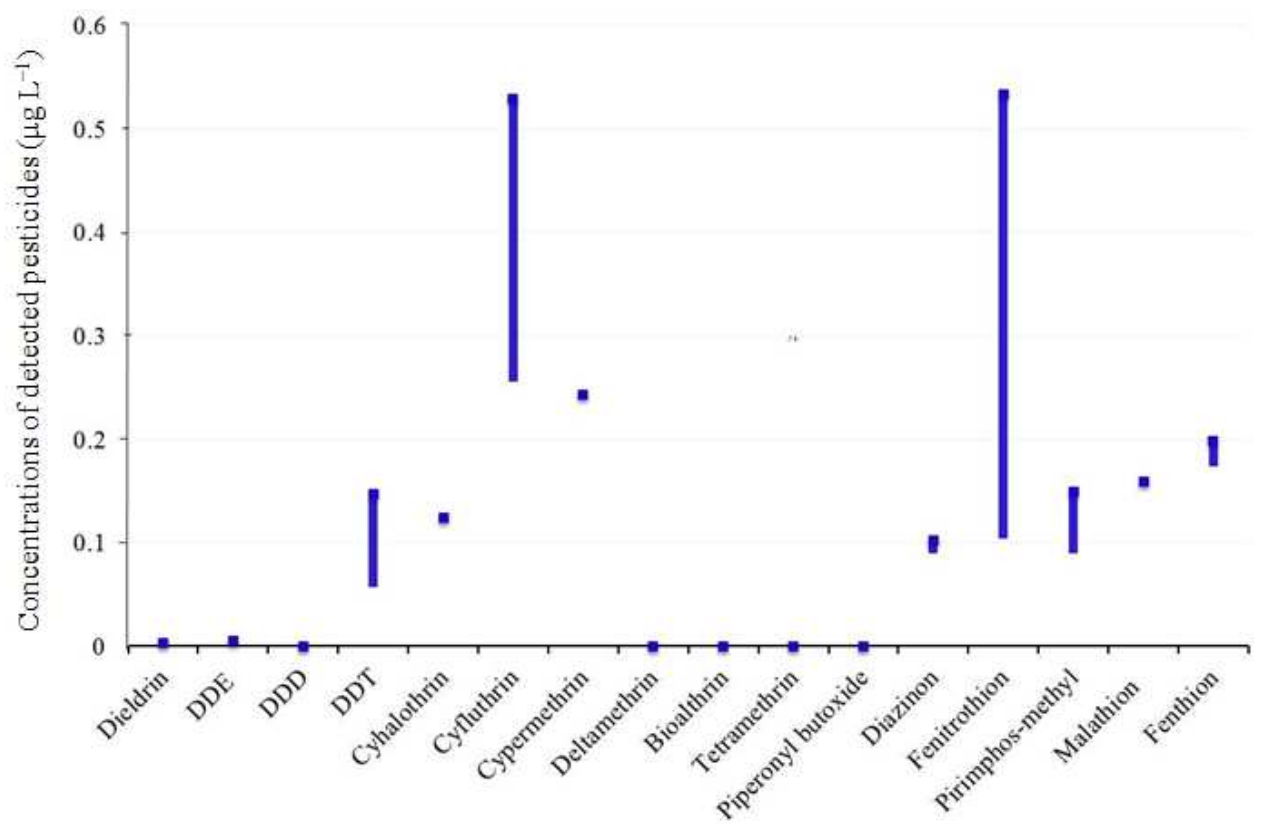

Fig. 4. Concentrations of selected insecticides in dams water samples $\left(\mu \mathrm{g} \mathrm{L}^{-1}\right)$ 


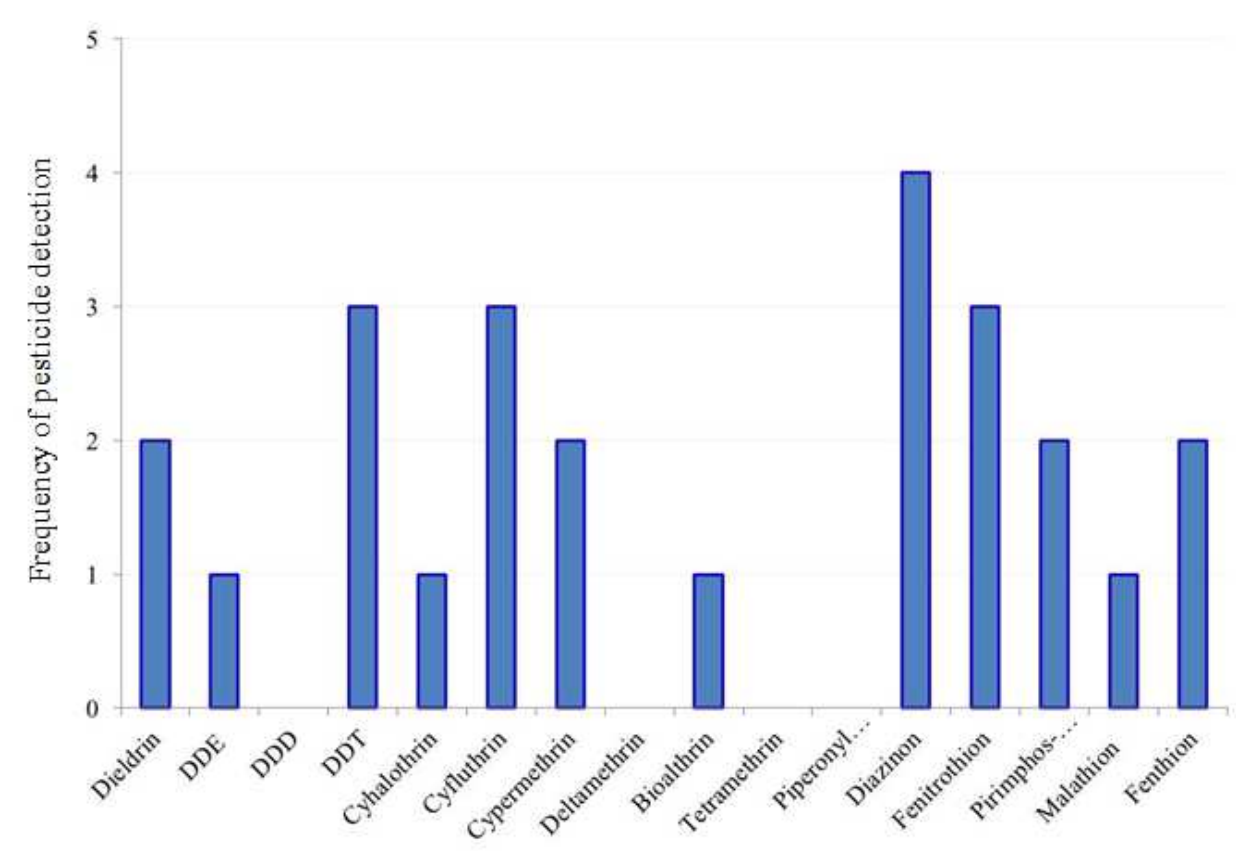

Fig. 5. Frequency of investigated compounds detection in dams water samples

\section{Discussion}

In the groundwater samples, fourteen insecticides of the 16 selected compounds were detected in at least 1 sample each in the 53 analysed samples. These results agree with other similar studies worldwide. Shukla et al. (2006) determined the contamination of groundwater in all samples collected from 28 domestic wells in Hyderabad, India, at concentrations ranging from $0.15-2.14 \mu \mathrm{g} \mathrm{L}^{-1}$ for 4 organochlorine pesticides: DDT, lindane, $\alpha$-Endosulfan and $\beta$-Endosulfan. Vryzas et al. (2012) reported that almost all water samples collected from 37 wells in Greece for 5 years were contaminated by pesticides at concentrations up to $5.2 \mu \mathrm{g} \mathrm{L}^{-1}$. Reemtsma et al. (2013) reported the same observation in Germany, where 58 samples of groundwater were contaminated at the median total concentrations of pesticide metabolites of $0.62 \mu \mathrm{g} \mathrm{L}^{-1}$. Morvan et al. (2006) reported the contamination of groundwater in France with atrazine and DEA at concentrations ranging from 0.07-1.16 $\mu \mathrm{g} \mathrm{L}^{-1}$. Moreover, 22 pesticides were detected in groundwater samples in Catalonia, Spain; pesticides, including diazinon, fenitrothion and malathion, were detected at concentrations of $4.4,13.3$ and $17.1 \mu \mathrm{g} \mathrm{L}^{-1}$ with a frequency of 51, 3 and $7 \%$, respectively.

Otherwise, in the samples collected from the surface water (dams), 11 compounds were detected at different concentrations ranging from $0.003-0.534 \mu \mathrm{g} \mathrm{L}^{-1}$. Results obtained in this study are in accord with other similar studies that reported the occurrence of pesticides in surface water. Jurado-Sanchez et al. (2012) reported contamination of surface water in Spain; the pesticides were found at concentrations ranging from $0.1-4 \mu \mathrm{g} \mathrm{L}^{-1}$ in the water samples prior to treatment in the drinking water plant. Robles-Molina et al. (2014) reported the detection of diazinon in 4 of 11 water samples collected from the Guadalquivir River in Spain in 2010 at a maximum concentration of $234.5 \mathrm{ng} \mathrm{L}^{-1}$ compared to $0.103 \mu \mathrm{g} \mathrm{L}^{-1}$ in this study. DDE was detected in $90 \%$ of the samples with a maximum concentration of 2.8 $\mathrm{ng} \mathrm{\textrm {L } ^ { - 1 }}$; in this study, the maximum concentration of

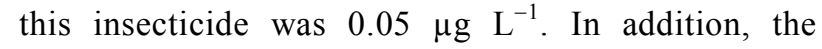
contamination of the Axion River in Macedonia, Northern Greece with pesticides has been reported; 4 pesticides (atrazine, alachlor, carbofuran and prometryne) were detected at concentrations exceeding $1 \mu \mathrm{g} \mathrm{L}^{-1}$ in the phreatie horizon (Papadopoulou-Mourkidou et al., 2004). In this study, the detected concentrations of pesticides in some samples slightly exceeded the allowed MRL of the EU, which is $0.1 \mu \mathrm{g} \mathrm{L}^{-1}$; but still lower than the limit of the sum of all individual compounds detected in the same sample of $0.5 \mu \mathrm{g} \mathrm{L}^{-1}$ (Fig. 3 and 4).

\section{Conclusion}

This study monitored the presence of pesticides in surface water and groundwater in the Jazan province, Saudi Arabia. The frequency of detected pesticides in groundwater was in the following order: Diazinon, dieldrin, fention, malathion, fenitrothion, pirimphos- 
methyl, cyfluthrin, bioalthrin, cyhalothrin, PBO, cypermethrin, DDT and DDD. While, the frequency of detected pesticides in surface water (dams) was: Diazinon, fenitrothion, cyfluthrin, DDT, dieldrin, cypermethrin, pirimphos-methyl, fenthion, DDE, cyhalothrin, bioalthrin and malathion. In general, detected concentrations of organophosphorus insecticides in all samples slightly exceeded the allowed MRL of the EU, but still lower than the limit of the sum of all individual compounds detected in the same sample. As a result, the groundwater and surface water in the Jazan area is safe for domestic use, drinking and irrigation. This work provides the first information on the presence and concentration of insecticides in groundwater and surface water (dams) of the Jazan area, Saudi Arabia, albeit at low concentrations and it shows the importance of more extended investigation. However, use of less persistent pesticides and the adoption of integrated pest management programs in Jazan area for the diseases vectors and other pests is highly recommended to reduce the contamination risk of waters resources with pesticides.

\section{Acknowledgment}

The authors thank King Abdul Aziz City for Science and Technology, General Directorate of Research Grants Programs for the financial support (grant № AT-11-24). We thank Moussa Al-Aqsum (Jazan University) for his assistance in mapping.

\section{Author's Contributions}

Hasan Y. Al-Hatim: Contributed in experiments design, sampling, lab preparation, analytical methods validation, samples analysis, collecting and interpretation of data.

Deifalla Alrajhi: Supervised the project and contributed in all phases of the work.

Abdul Jabbar Al-Rajab: Contributed in interpretation of data, manuscript writing and submission corresponding.

\section{Ethics}

This article is original and contains unpublished material. The corresponding author confirms that all of the other authors have read and approved the manuscript and no ethical issues involved.

\section{References}

Abhilash, P.C. and N. Singh, 2009. Pesticide use and application: An Indian scenario. J. Hazardous Mater., 165: 1-12.

DOI: 10.1016/j.jhazmat.2008.10.061
Akesson, M., C.J. Sparrenbom, C. Carlsson and J. Kreuger, 2013. Statistical screening for descriptive parameters for pesticide occurrence in a shallow groundwater catchment. J. Hydrol., 477: 165-174. DOI: $10.1016 /$ j.jhydrol.2012.11.025

Al-Rajab, A.J. and M. Schiavon, 2010. Degradation of ${ }^{14} \mathrm{C}$-glyphosate and Aminomethylphosphonic Acid (AMPA) in three agricultural soils. J. Environ. Sci., 22: 1374-1380. DOI: 10.1016/S1001-0742(09)60264-3

Al-Rajab, A.J. and O.M. Hakami, 2014. Behavior of the non-selective herbicide glyphosate in agricultural soil. Am. J. Environ. Sci., 10: 94-101. DOI: 10.3844/ajessp.2014.94.101

Al-Rajab, A.J., S. Amellal and M. Schiavon, 2008. Sorption and leaching of ${ }^{14} \mathrm{C}$-glyphosate in agricultural soils. Agronomy Sustainable Dev., 28: 419-428. DOI: 10.1051/agro:2008014

Belenguer, V., F. Martinez-Capel, A. Masia and Y. Pico, 2014. Patterns of presence and concentration of pesticides in fish and waters of the Júcar River (Eastern Spain). J. Hazardous Mater., 265: 271-9. DOI: 10.1016/j.jhazmat.2013.11.016

Daam, M.A., E. Silva, S. Leitao, M.J. Trindade and M.J. Cerejeira, 2010. Does the actual standard of $0.1 \mu \mathrm{g} / \mathrm{L}$ overestimate or underestimate the risk of plant protection products to groundwater ecosystems? Ecotoxicol. Environ. Safety, 73: 750-6. DOI: $10.1016 /$ j.ecoenv.2009.12.029

EC, 2006. Directive 2006/118/EC of the European Parliament and of thecouncil of $12^{\text {th }}$ of December 2006 on the protection of groundwater against pollution and deterioration. J. Eur. Union L, 372: 19-19.

Fenoll, J., P. Flores, P. Hellín, J. Hernández and S. Navarro, 2014. Minimization of methabenzthiazuron residues in leaching water using amended soils and photocatalytic treatment with $\mathrm{TiO}_{2}$ and $\mathrm{ZnO}$. J. Environ. Sci., 26: 757-764. DOI: $10.1016 /$ S1001-0742(13)60511-2

Jurado-Sanchez, B., E. Ballesteros and M. Gallego, 2012. Occurrence of aromatic amines and Nnitrosamines in the different steps of a drinking water treatment plant. Water Res., 46: 4543-4555. DOI: 10.1016/j.watres.2012.05.039

Köck-Schulmeyer, M., A. Ginebreda, C. Postigo, T. Garrido and J. Fraile et al., 2014. Four-year advanced monitoring program of polar pesticides in groundwater of Catalonia (NE-Spain). Sci. Total Environ., 470-471: 1098-87. DOI: $10.1016 /$ j.scitotenv.2013.10.079

Malaguerra, F., H.J. Albrechtsen, L. Torling and P.J. Binning, 2012. Pesticides in water supply wells in Zealand, Denmark: A statistical analysis. Sci. Total Environ., 414: 433-444. DOI: $10.1016 /$ j.scitotenv.2011.09.071 
Morvan, X., C. Mouvet, N. Baran and A. Gutierrez, 2006. Pesticides in the groundwater of a spring draining a sandy aquifer: Temporal variability of concentrations and fluxes. J. Contaminant Hydrol., 87: 176-190. DOI: 10.1016/j.jconhyd.2006.05.003

Otieno, P., P. OkindaOwuor, J.O. Lalah, G. Pfister and K.W. Schramm, 2014. Monitoring the occurrence and distribution of selected organophosphates and carbamate pesticide residues in the ecosystem of Lake Naivasha, Kenya. Toxicol. Environ. Chem., 97: 51-61. DOI: 10.1080/02772248.2014.942309

Papadopoulou-Mourkidou, E., D.G. Karpouzas, J. Patsias, A. Kotopoulou and A. Milothridou et al., 2004. The potential of pesticides to contaminate the groundwater resources of the Axios river basin in Macedonia, Northern Greece. Part I. Monitoring study in the north part of the basin. Sci. Total Environ., 321: 127-146. DOI: $10.1016 /$ j.scitotenv.2003.08.019

Reemtsma, T., L. Alder and U. Banasiak, 2013. Emerging pesticide metabolites in groundwater and surface water as determined by the application of a multimethod for 150 pesticide metabolites. Water Res., 47: 5535-5545.

DOI: $10.1016 /$ j.watres.2013.06.031

Robles-Molina, J., B. Gilbert-Lopez, J.F. Garcia-Reyes and A. Molina-Diaz, 2014. Monitoring of selected priority and emerging contaminants in the Guadalquivir River and other related surface waters in the province of Jaén, South East Spain. Sci. Total Environ., 479-480: 247-57. DOI: $10.1016 /$ j.scitotenv.2014.01.121

Sahoo, G.B., C. Ray and H.F. Wade, 2005. Pesticide prediction in ground water in North Carolina domestic wells using artificial neural networks. Ecol. Modell., 183: 29-46.

DOI: 10.1016/j.ecolmodel.2004.07.021

Sarigiannis, D.A., P. Kontoroupis, E.S. Solomou, S. Nikolaki and A. J.Karabelas, 2013. Inventory of pesticide emissions into the air in Europe. Atmospheric Environ., 75: 6-14.

DOI: $10.1016 /$ j.atmosenv.2013.04.003
Seth, P., 2014. Chemical Contaminants in Water and Associated Health Hazards. In: Water and Health, Singh, P.P. and V. Sharma (Eds.), Springer, India, pp: 375-384.

Shukla, G., A. Kumar, M. Bhanti, P.E. Joseph and A. Taneja, 2006. Organochlorine pesticide contamination of ground water in the city of Hyderabad. Environ. Int., 32: 244-247.

DOI: 10.1016/j.envint.2005.08.027

Van Stempvoort, D.R., J.W. Roy, S.J. Brown and G. Bickerton, 2014. Residues of the herbicide glyphosate in riparian groundwater in urban catchments. Chemosphere, 95: 455-63.

DOI: 10.1016/j.chemosphere.2013.09.095

Vryzas, Z., E.N. Papadakis, G. Vassiliou and E. Papadopoulou-Mourkidou, 2012. Occurrence of pesticides in transboundary aquifers of Northeastern Greece. Sci. Total Environ., 441: 41-48. DOI: 10.1016/j.scitotenv.2012.09.074

Worrall, F. and T. Besien, 2005. The vulnerability of groundwater to pesticide contamination estimated directly from observations of presence or absence in wells. J. Hydrol., 303: 92-107.

DOI: 10.1016/j.jhydrol.2004.08.019

Yadav, I.C., N.L. Devi, J.B. Syed, Z. Cheng and J. Li et al., 2015. Current status of persistent organic pesticides residues in air, water and soil and their possible effect on neighboring countries: A comprehensive review of India. Sci. Total Environ., 511: 123-137. DOI: 10.1016/j.scitotenv.2014.12.041

Zhao, Y.Y. and Y.S. Pei, 2012. Risk evaluation of groundwater pollution by pesticides in China: A short review. Procedia Environ. Sci., 13: 1739-1747. DOI: $10.1016 /$ j.proenv.2012.01.167 